\title{
An new swarm intelligent algorithm to solve the efficiency Nash equilibrium of single-leader-multi-follower game
}

\author{
Liu luping ${ }^{1}$ and Jia Wensheng ${ }^{1}$ \\ ${ }^{1}$ Guizhou University
}

September 4, 2020

\begin{abstract}
This paper presents the particle swarm optimization algorithm and immune particle swarm optimization algorithm (PSO-IPSO) to solve the single-leader-multi-follower game (SLMFG). The PSO-IPSO algorithm is designed by combining particle swarm algorithm and immune memory mechanism, and the diversity of the population is maintained by using probability density selection function. Meanwhile, we define the efficiency Nash equilibrium by using the idea of efficiency, which is more beneficial to all players and greatly refine Nash equilibrium. Finally, numerical experiments show that this algorithm not only does not rely on the choice of an initial point, but also increases the diversity of swarm to keep global convergence, and the PSO-IPSO algorithm is fast convergence speed and effective.
\end{abstract}

\section{Hosted file}

Manuscript.pdf available at https://authorea.com/users/356175/articles/479148-an-new-swarmintelligent-algorithm-to-solve-the-efficiency-nash-equilibrium-of-single-leader-multifollower-game

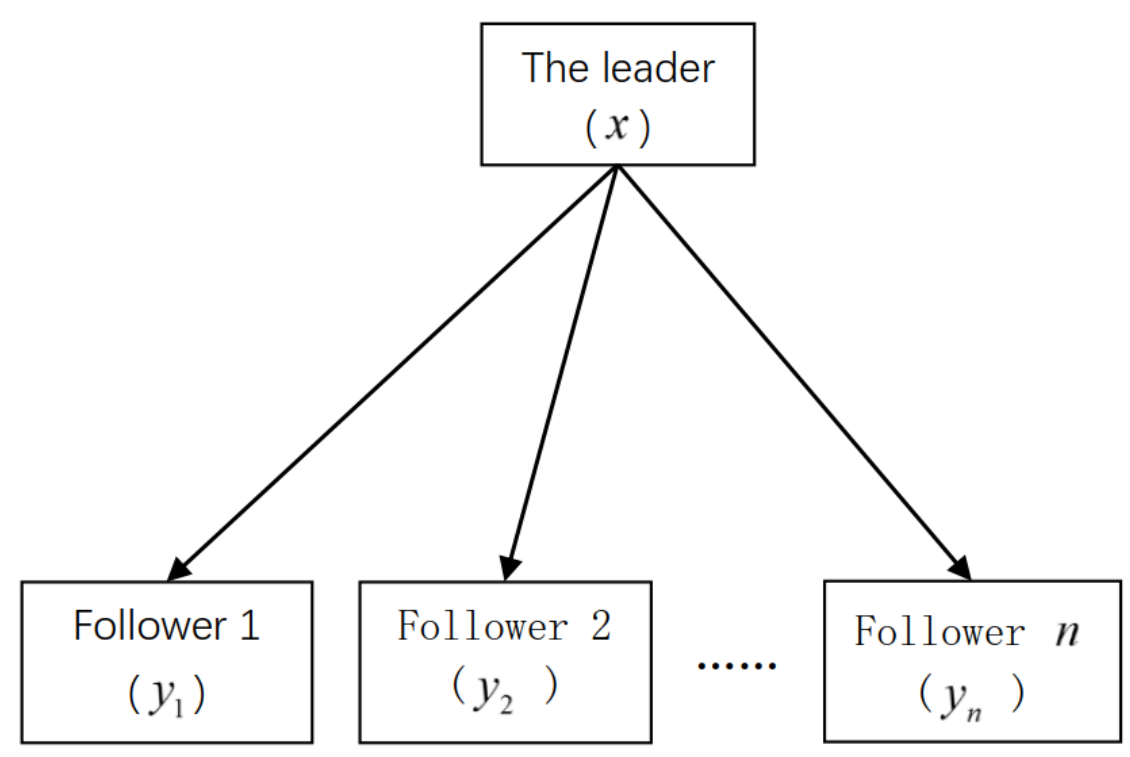




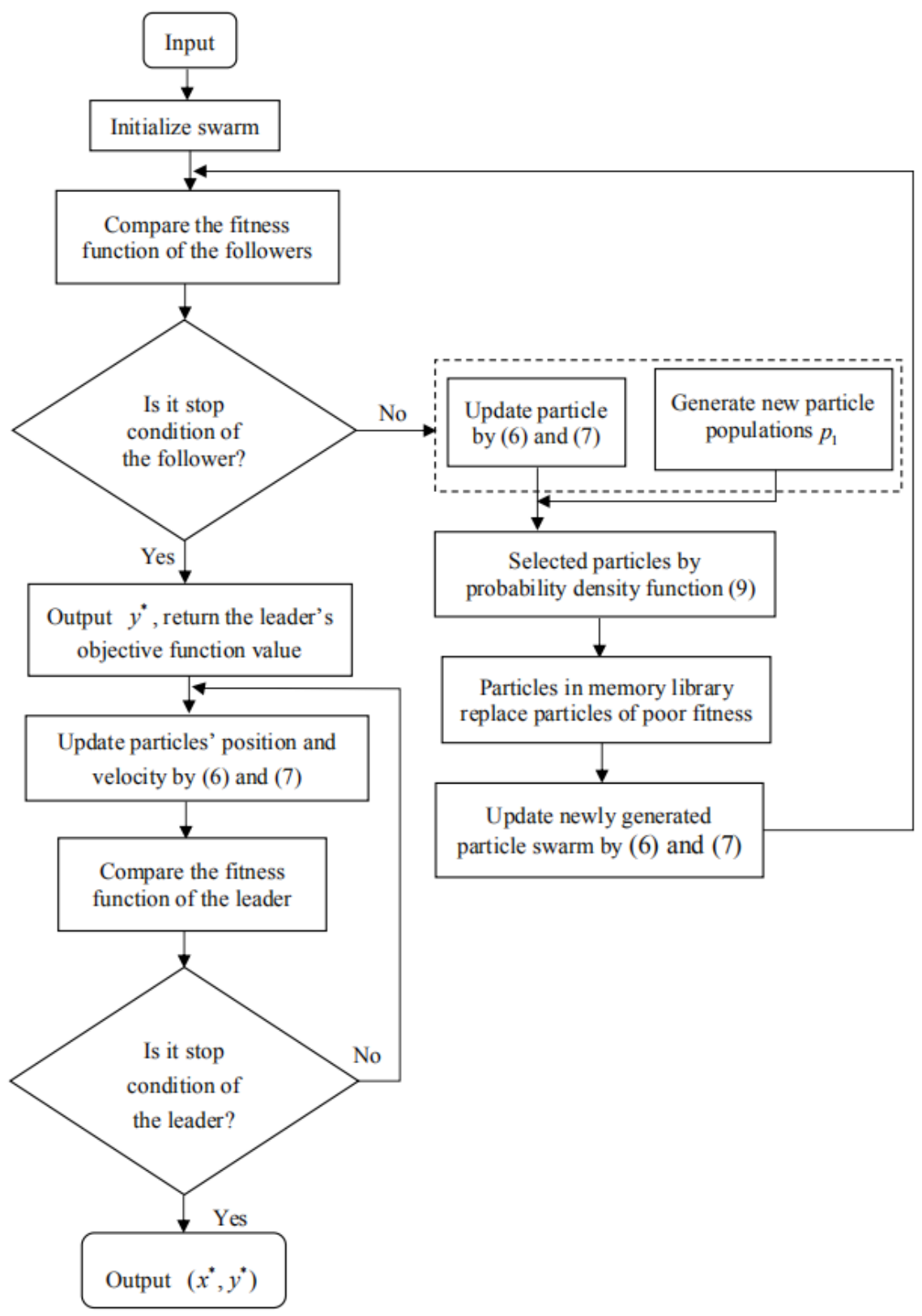



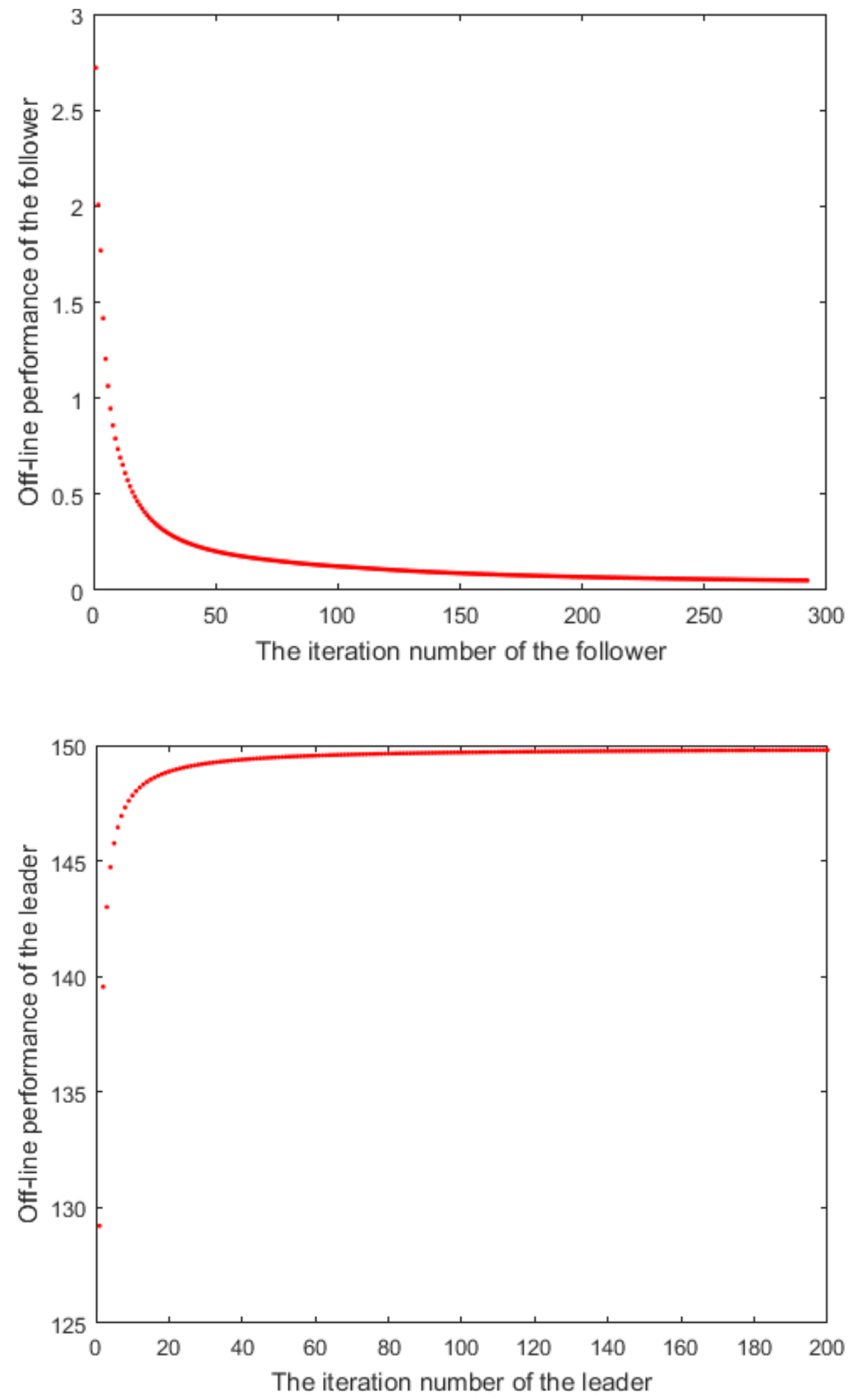